\title{
Pemberdayaan Masyarakat dalam Pembangunan Berkelanjutan melalui Pemanfaatan Daun Kelor (Moringa Oleifera) di Desa Kedung Sumber, Balongpanggang, Gresik
}

\author{
Nur Cahyadi'), Heru Baskoro²) \\ 1) Fakultas Kesehatan Universitas Muhamadiyah Gresik, nurcahyadi@umg.ac.id \\ 2) Fakultas Kesehatan Universitas Muhamadiyah Gresik, herbas.gresik@umg.ac.id
}

\begin{abstract}
ABSTRAK
Pemberdayaan masyarakat dalam pembangunan berkelanjutan tidak akan sukses tanpa adanya peran serta warga, baik perangkat desa, kader dan masyarakat itu sendiri. Pemberdayaan masyarakat merupakan upaya untuk menciptakan/meningkatkan kapasitas masyarakat dalam rangka peningkatan kemandirian, baik secara individu maupun berkelompok. Rendahnya pengetahuan dan pemahaman masyarakat Desa Kedung Sumber Balongpanggang Gresik mengenai pemanfaatan sumber daya alam yang ada di wilayahnya mendorong dilaksanakan kegiatan pengabdian kepada masyarakat ini. Melalui penyuluhan, pelatihan, dan pendampingan, masyarakat di Desa Kedung Sumber diberdayakan untuk mampu menghasilkan berbagai produk dengan menggunakan bahan baku daun kelor yang merupakan sumber daya lokal. Produk yang dihasilkan diantaranya adalah ice cream, puding dan nugget. Melalui kegiatan ini masyarakat setempat diharapkan mampu menghasilkan produk-produk yang bernilai ekonomi untuk meningkatkan kemandirian masyarakat, baik secara individu maupun berkelompok.
\end{abstract}

Kata-kata Kunci : Pemberdayaan, Pemanfaatan, Penyuluhan, Pendampingan

\begin{abstract}
Community empowerment in sustainable development will not be successful without citizens' participation, both village officials, cadres and the community itself. Community empowerment is an effort to increase the community independency, both individually and in a group. The lack of knowledge and understanding the residence of Kedung Sumber Village, Balongpanggang, Gresik regarding the use of natural resources around them, encuorages this community empowerment program. Moringa Oleifera is a local resources that could be utilized in improving the welfare of the community. This community empowerment program introduces the way how to create some products using Moringa Oleifera. Some products than can be produced are ice cream, puding, and nugget. Therefore, this program is expected to increase the community independency, both individually and in a group.
\end{abstract}

Keywords : Empowerment, Utilization, Counseling, Assistance

\section{PENDAHULUAN}

Pembangunan berkelanjutan merupakan suatu masalah yang kompleks, seperti halnya dari segi manajemen yang memerlukan perencanaan, pelaksanaan, monitoring dan evaluasi. Saat ini masyarakat yang semula diposisikan sebagai obyek dalam pembangunan menjadi subyek pembangunan yang bersifat efektif dengan strategi pemberdayaan masyarakat. Pemilihan strategi yang tepat dapat meningkatkan kemampuan dan kemandirian masyarakat. Pemberdayaan masyarakat merupakan upaya dalam pembangunan untuk menciptakan/meningkatkan kapasitas masyarakat, memperbaiki situasi dan kondisi dalam peningkatan kemandirian masyarakat baik secara individu maupun berkelompok, dalam menyelesaikan berbagai persoalan terkait upaya peningkatan kualitas 
hidup, kemandirian dan kesejateraannya. Selain itu juga dengan adanya strategi pemberdayaan masyarakat dapat memunculkan ruang dan kapasitas untuk mengembangkan potensi baik sumber daya manusia maupun sumber daya alam, dapat menyelesaikan masalah secara mandiri. Proses pemberdayaan masyarakat tidak dapat berjalan dengan sukses dan berkelanjutan tanpa adanya keterlibatan dari berbagai pihak. Salah satu cara adalah dengan membangun kemitraan dan jaringan dengan pihak eksternal seperti menjalin kerja sama dengan perguruan tinggi baik negeri maupun swasta berupa program pengabdian kepada masyarakat yang dilakukan oleh dosen dan mahasiswa untuk memenuhi kewajibannya dalam pelaksanaan tri dharma perguruan tinggi.

Desa Kedung Sumber Kecamatan Balongpanggang Kabupaten Gresik Jawa Timur merupakan salah satu desa yang memiliki potensi sumber daya alam yang dapat dimanfaatkan secara maksimal berupa tanaman daun kelor (Moringa Oleifera). Berdasarkan observasi, terlihat bahwa pengetahuan dan pemahaman masyarakat mengenai pemanfaatan sumber daya alam di wilayah Desa Kedung Sumber yang seharusnya dapat meningkatkan kesejahteraan masyarakat baik secara ekonomi maupun kesehatan, masih rendah. Adanya cara pandang masyarakat terhadap potensi lokal berupa daun kelor yang dihubungkan dengan hal-hal mistis seperti daun kelor digunakan untuk pengusir setan dan sihir. Kurangnya kreativitas dan inovasi masyarakat dalam pemanfaatan produk lokal daun kelor yang hanya digunakan sebagai sayur bening daun kelor, dan juga pemanfaatan daun kelor digunakan sebagai bahan pakan hewan ternak yang dimiliki oleh masyarakat Desa Kedung Sumber Balongpanggang. Hasil observasi menunjukkan diperlukannya suatu tindakan untuk mendukung usaha dalam peningkatan pengetahuan dan pemahaman masyarakat agar terwujudnya masyarakat yang mandiri dan sejahtera, terciptanya ide, inovasi dan kreativitas masyarakat dalam pengolahan dan pemanfaatan potensi lokal salah satunya adalah dengan pelaksanaan kegiatan penyuluhan dan pendampingan.

Tanaman kelor (Moringa Oleifera) merupakan salah satu jenis tanaman tropis yang mudah tumbuh di daerah tropis seperti Indonesia. Tanaman kelor merupakan tanaman perdu dengan ketinggian 7-11 meter dan tumbuh subur mulai dari dataran rendah sampai ketinggian $700 \mathrm{~m}$ di atas permukaan laut. Kelor dapat tumbuh pada daerah tropis dan subtropis pada semua jenis tanah dan tahan terhadap musim kering dengan toleransi terhadap kekeringan sampai 6 bulan (Aminah, Ramdhan, \& Yanis, 2015). Beberapa komponen yang terkandung dalam bagian tanaman kelor dapat memberikan efek kesehatan berupa : menurunkan berat badan, anti diabetes, mencegah penyakit jantung, menyehatkan rambut, menyehatkan mata, mengobati rematik, mengobati herpes/kurap, mengobati penyakit dalam seperti luka lambung, luka usus dan batu ginja dan mengobati kanker (Isnan \& Nurhaedah, 2017) 


\section{METODE PELAKSANAAN}

Kegiatan pengabdian kepada masyarakat ini dilakukan dengan menggunakan pendekatan ceramah dan diskusi berdasarkan pada prinsip sharing knowledge artinya tim menempatkan diri pada posisi dimana pelaksana kegiatan dalam membantu masyarakat dengan belajar bersama tidak memposisikan yang paling dominan. Metode ini dipilih karena pada dasarnya masyarakat mempunyai peran penting dalam memecahkan masalah yang dihadapinya. Kegiatan ini dilaksanakan di Desa Kedung Sumber Kecamatan Balongpanggang Kabupaten Gresik Jawa Timur. Kegiatan tersebut melibatkan pihak terkait antara lain yaitu:
a. Perangkat Desa Kedung Sumber
b. Tenaga Kesehatan Wilayah Desa Kedung Sumber
c. Kader Posyandu Wilayah Desa Kedung Sumber
d. Masyarakat Desa Kedung Sumber

\section{HASIL DAN PEMBAHASAN}

\subsection{Gambaran Umum}

Wilayah Desa Kedung Sumber menurut geografis terletak di Kecamatan Balongpanggang Kabupaten Gresik dengan batas-batas sebagai berikut:

$\begin{array}{ll}\text { Sebelah Utara } & \text { : Desa Pacuh } \\ \text { Sebelah Selatan } & \text { : Desa Mojogede } \\ \text { Sebelah Timur } & \text { : Desa Balongpanggang } \\ \text { Sebelah Barat } & \text { : Desa Babatan }\end{array}$

Luas Desa Kedung Sumber adalah 517,5 Ha yang terdiri dari 4 dusun yaitu :

Dusun Kedung Sumber Timur terdiri dari 6 RT

Dusun Kedung Sumber Barat terdiri dari 5 RT

Dusun Kedung Watu terdiri dari 4 RT

Dusun Gowah terdiri dari 3 RT

\subsection{Penduduk}

Jumlah penduduk Desa Kedung Sumber pada tahun 2019 adalah 2307 jiwa, dengan jumlah kepala keluarga sebanyak 759. Tabel 1 menunjukkan jumlah penduduk menurut golongan usia dan jenis kelamin. 
Tabel 1. Jumlah Penduduk menurut Golongan Umur dan Jenis Kelamin

\begin{tabular}{|c|c|c|c|c|}
\hline \multirow{2}{*}{ No } & \multirow{2}{*}{ Golongan Umur } & \multicolumn{2}{|c|}{ Tahun 2018} & \multirow{2}{*}{ Jumlah } \\
\cline { 3 - 4 } & & Laki-Laki & Perempuan & \\
\hline 1 & 0 bulan -12 bulan & 16 & 19 & 35 \\
\hline 2 & 13 bulan -4 tahun & 47 & 48 & 95 \\
\hline 3 & 5 tahun -9 tahun & 107 & 106 & 213 \\
\hline 4 & 10 tahun -14 tahun & 95 & 126 & 221 \\
\hline 5 & 15 tahun -19 tahun & 123 & 109 & 232 \\
\hline 6 & 20 tahun -24 tahun & 93 & 87 & 180 \\
\hline 7 & 25 tahun -29 tahun & 94 & 87 & 181 \\
\hline 8 & 30 tahun -34 tahun & 104 & 105 & 209 \\
\hline 9 & 35 tahun -39 tahun & 105 & 103 & 208 \\
\hline 10 & 40 tahun -44 tahun & 135 & 130 & 265 \\
\hline 11 & 45 tahun -49 tahun & 113 & 112 & 225 \\
\hline 12 & 50 tahun -54 tahun & 122 & 121 & 243 \\
\hline & Total & $\mathbf{1 1 5 4}$ & $\mathbf{1 1 5 3}$ & $\mathbf{2 3 0 7}$ \\
\hline
\end{tabular}

Sumber : Kantor Desa Kedung Sumber, 2019

\subsection{Pelaksanaan Kegiatan}

Kegiatan pengabdian kepada masyarakat dilaksanakan di Balai Desa Kedung Sumber Jl. Raya Kedung Sumber RT. 02 RW. 01 Kecamatan Balongpanggang Gresik dimulai pada Bulan Juli - Oktober 2019. Berikut ini uraian kegiatan yang telah dilaksanakan.

1. Penyuluhan

Kegiatan ini memberikan informasi dan pemahaman tentang pentingnya pemanfaatan bahan lokal terutama daun kelor agar mempunyai nilai jual dan manfaat (Gambar 1).

\section{Pendampingan}

Kegiatan pendampingan lebih menitik beratkan pada upaya peningkatan pengetahuan dan perbaikan yang berkaitan dengan pemanfaatan bahan lokal daun kelor. Kegiatan pendampingan dalam hal ini adalah berupa diskusi dan konsultasi sekitar cara pemanfaatan bahan lokal (Gambar 2).
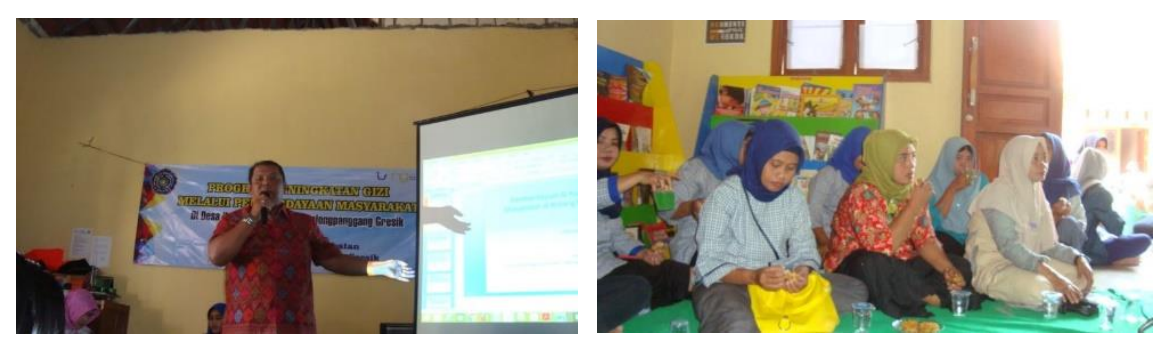

Gambar 1.

Kegiatan Penyuluhan Pemanfaatan Bahan Lokal 

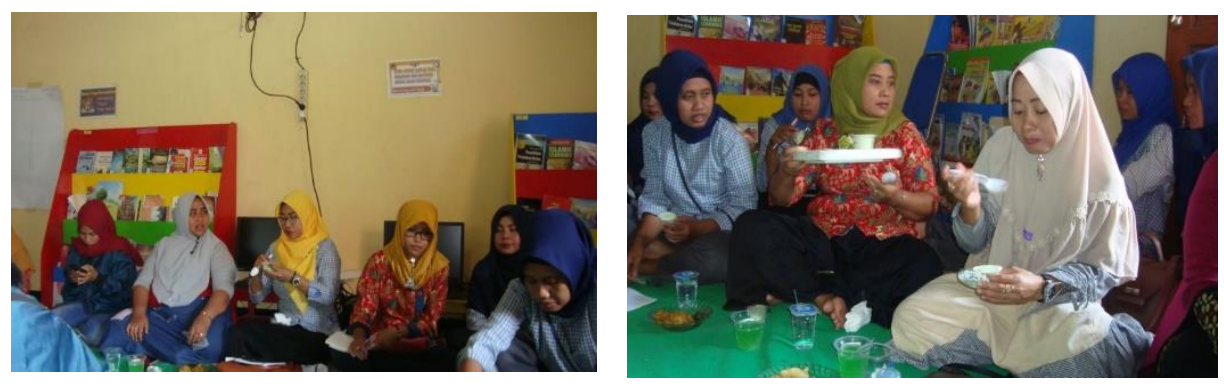

Gambar 2.

Kegiatan Pendampingan Pemanfaatan Bahan Lokal

3. Pelatihan

Pada kegiatan ini lebih ditekankan memberikan bekal atau kemampuan dalam mengolah bahan lokal berupa daun kelor. Dimana produk yang dapat dihasilkan dari daun kelor adalah ice cream, pudding dan nugget, diharapkan masyarakat dapat mempunyai ide kreasi dan inovasi baru dalam pemanfaatan bahan lokal berupa daun kelor.
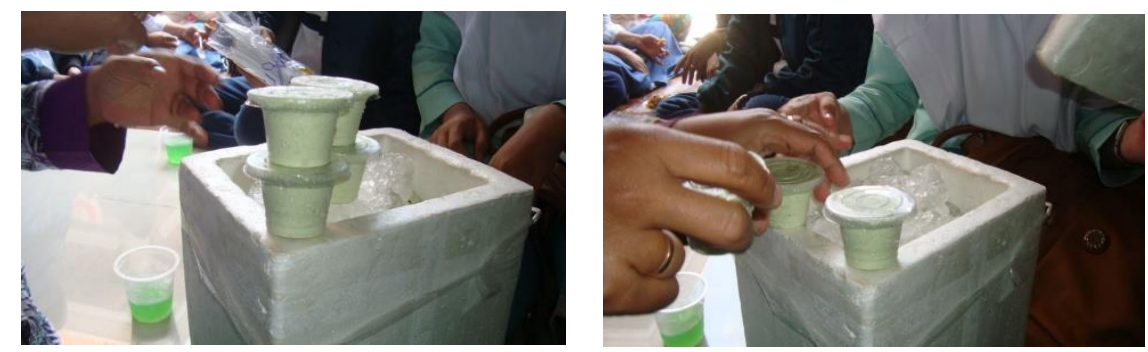

Gambar 3.

Kegiatan Pelatihan Pemanfaatan Bahan Lokal

\subsection{Kendala yang Dihadapi}

Program pemberdayaan masyarakat tidak terlepas dari berbagai hambatan dan kendala yang dihadapi. Kendala yang terjadi dalam pelaksanaan program pemberdayaan masyarakat dapat berasal dari kepribadian masing-masing individu maupun kelompok/komunitas. Kendala-kendala tersebut diantaranya yaitu:

a. Kurangnya kesadaran masyarakat dalam keikutsertaan menjalankan kegiatan

b. Sikap penolakan terhadap orang luar, adanya rasa curiga dan terganggu dengan keberadaan tim

c. Rasa tidak percaya diri dengan kemampuannya sehingga sulit dalam menggali dan memunculkan potensi yang ada pada diri individu.

d. Kecenderungan tidak mau atau sulit menerima perubahan dan pembaharuan.

e. Sikap kekhawatiran akan kehilangan adat dan kebiasaan jika menerima unsur-unsur baru.

f. Tingkat pendidikan yang tidak merata, sehingga pemahaman dan pengetahuan masyarakat masih rendah. 


\subsection{Dampak Pemberdayaan Masyarakat}

Hasil kegiatan pengabdian kepada masyarakat mempunyai dampak diantaranya yaitu sebagai berikut:

a. Mengubah pola pikir masyarakat ke arah yang lebih maju, dimana masyarakat mampu mengorganisasi dirinya sendiri dan kemandirian dalam bidang ekonomi dari masingmasing individu.

b. Masyarakat menjadi aktif dalam berinteraksi sosial dengan masyarakat lainnya sehingga terciptanya solidaritas diantara anggota masyarakat.

c. Mengembangkan potensi bahan lokal dengan merubah pola pikir yang lebih luas dalam memunculkan ide, kreatif dan inovasi.

d. Menghasilkan produk yang bernilai ekonomis dengan berbagai varian dari bahan lokal.

\subsection{Upaya Keberlanjutan Kegiatan}

Perencanaan program dilaksanakan secara berkelanjutan dengan prinsip dari masyarakat, oleh masyarakat, dan untuk masyarakat. Upaya yang dapat dilakukan diantaranya yaitu :

a. Pendampingan

Berperan sebagai fasilitator pada kegiatan pendampingan. Hal ini sangat dibutuhkan oleh masyarakat, seperti halnya pemberian motivasi, kesempatan dan dukungan bagi masyarakat. Bertukar gagasan pengetahuan dan pengalaman masyarakat, membangkitkan kesadaran masyarakat dalam pemanfaatan bahan lokal, penyampaian informasi serta berperan menemani masyarakat dalam melaksanakan setiap tahapan proses pemberdayaan.

b. Pelatihan

Pelatihan sebagai suatu cara yang digunakan untuk memberikan atau meningkatkan ketrampilan yang dibutuhkan untuk melaksanakan pekerjaan sekarang (Wardhani, Sumartono, \& Makmur, 2015) . Upaya pelaksanaan pelatihan dapat meningkatkan kapasitas masyarakat dalam pengetahuan, keterampilan, dan sikap, sehingga akan muncul ide-ide kreatif dan inovasi baru dalam pemanfaatan bahan lokal khusunya daun kelor.

\section{KESIMPULAN}

Kegiatan pengabdian kepada masyarakat dilakukan di Desa Kedung Sumber Kecamatan Balongpanggang Kabupaten Gresik selama 4 bulan mulai bulan Juli-Oktober 2019. Uraian kegiatan meliputi penyuluhan, pendampingan, dan pelatihan. Kegiatan ini diharapkan dapat meningkatkan kemandirian dan kesejahteraan masyarakat desa yang 
berkelanjutan melalui pemberdayaan masyarakat secara optimal. Pemanfaatan bahan lokal yang selama ini dipandang sebelah mata dan tidak bernilai, diharapkan melalui kegiatan pemberdayaan masyarakat dapat menghasilkan produk-produk yang bernilai ekonomis untuk mencapai masyarakat yang sejahtera dan mandiri.

\section{UCAPAN TERIMA KASIH}

Terima kasih disampaikan kepada Pimpinan Universitas Muhammadiyah Gresik, Kepala LP2M, Kepala Bagian Pengabdian Kepada Masyarakat UMG, serta masyarakat Desa Kedung Sumber Kecamatan Balongpanggang baik perangkat desa, tenaga kesehatan, dan kader Posyandu. Semoga bantuan dan kerjasamanya dalam pelaksanaan kegiatan ini mempunyai manfaat bagi masyarakat. Harapan kami kegiatan semacam ini dapat dilakukan secara berkelanjutan.

\section{REFERENSI}

Aminah, S., Ramdhan, T., Yanis, M. (2015). Kandungan Nutrisi dan Sifat Fungsional Tanaman Kelor (Moringa Oleifera ). Buletin Pertanian Perkotaan, 5(30), 35-44. Isnan, W., Nurhaedah. (2017). Ragam Manfaat Tanaman Kelor ( Moringa Oleifera Lamk.) Bagi Masyarakat. Info Teknis EBONI, 14, 63-75.

Wardhani, C. H., Sumartono, S., Makmur, M. (2015). Manajemen Penyelenggaraan Program Pelatihan Masyarakat (Studi di Balai Besar Pemberdayaan Masyarakat dan Desa Kementerian Dalam Negeri di Malang). Wacana, Jurnal Sosial Dan Humaniora, 18(01), 21-30. Diunduh dari https://doi.org/10.21776/ub.wacana.2015.018.01.3 